\title{
Heavy Metal Enrichment Characteristics of Poplar
}

\author{
Jianhua Wang \\ The School of Earth and Environmental \\ Anhui University of Science and Technology \\ Huainan, Anhui,China \\ line 3: City, Country \\ Jinxiang Yang * \\ The School of Earth and Environmental \\ Anhui University of Science and Technology \\ Huainan, Anhui,China \\ yangjx2027@163.com \\ * Corresponding Author
}

\author{
Xiaolong $\mathrm{Li}$ \\ The School of Earth and Environmental \\ Anhui University of Science and Technology \\ Huainan, Anhui,China
}

\begin{abstract}
Soil heavy metal pollution has become a focus of attention in the world. The poplar trees have some characteristics: easiness to plant, quick growth, strong resistance, and large biomass. Therefore, the poplar is taken as the example and this paper studies the enrichment characteristics of different heavy metalspaper. The results are shown that: (1) the enrichment ability of heavy metals by polar is: zinc > copper > cadmium > lead > nickel > chromium. As for different parts, the heavy metal enrichment capability of leaf is the largest. (2) The transfer ability of heavy metals by polar is: copper > cadmium> zinc $>$ lead $>$ nickel $>$ chromium. Among them, the transfer coefficient of chromium by poplar stem is the largest, and leaf has the maximum transfer coefficient on the rest five heavy metals. In summary, the results indicate that zinc, copper and cadmium are the enrichment heavy metals of polar.
\end{abstract}

Keywords-Heavy Metal Pollution; Characteristic; Poplar; Phytoremediation; Soil

Enrichment

\section{INTRODUCTION}

Refers to the soil heavy metal pollution due to human activities will be all kinds of heavy metals into the soil, the soil heavy metal content in the enrichment to increase significantly higher than that of soil background content and cause of the deterioration of the ecological environment quality pollution phenomenon ${ }^{[1]}$. International research on soil heavy metal pollution and repair began in the $1970 \mathrm{~s}{ }^{[2]}$. Woody plants technology research started later, it was first been put forward by Nguyen et al.[3], in order to distinguish the herb repair plant. As time goes by, it caused the wide attention of scholars both at home and abroad. In 1995, Punshon[4] first developed a hydroponic screening methods, such as, selection willow with the resistance of $\mathrm{Cu}$. Sweden's Tommy Landberg[5] studied different willow (Salix) in different soils concentration enrichment of $\mathrm{Cd}$, found that some species plant of the willows (Salix) can enrichment a mass of $\mathrm{Cd}$, and the absorbing state of different genotypes was different on the $\mathrm{Cd}$. Yu Guoying [6] conducted a study about poplar body heavy metal ele ment inside and outside the migration cycle during before and after the fallen leaves. Research found that as a fast-growing tree of the poplar the accumulation of $\mathrm{Cd}$ and $\mathrm{Hg}$ reached $34.93 \mathrm{mg} / \mathrm{kg}$ and $47.19 \mathrm{mg} / \mathrm{kg}$, exceeded the controlled plants more than 10 times, growth and biomass not trouble find.

Therefore, this paper takes an example of poplar, according to poplar root, rhizo me, diameter at breast height, branch and leaf five parts of the heavy metal content, analysis of heavy metals in different parts of the poplar distribution; On this basis, according to the different parts of the heavy metal content and the corresponding soil heavy metal content, this paper analyzes the heavy metal enrichment coefficient and transfer coefficient, and studies the heavy metal enrichment characteristics of poplar, in order to provide reference base for the phytoremediation of soil heavy metals pollution.

\section{MATERIALS AND METHODS}

\section{A. Materials}

In Huainan reclamation-area, screening plant grew well. This paper collected about twenty Poplars respectively by the root, rhizome, stem, branches and leaves, and then puted into the sample bags, and brought back to the lab for testing.

\section{B. Methods}

According to the research purpose to processing parts with these acquisition of plant sample, this paper first uses tap water to wash away the dust and soil that attached on the surface, once more use a secondary deionized water rinse it $\mathrm{t}$ wice, and then with stainless steel kn ife chop after natural air, weight about $200 \mathrm{~g}$ in ceramic disk. After filming in the $105{ }^{\circ} \mathrm{C}$ for $30 \mathrm{~min}$, drum bellows in $50{ }^{\circ} \mathrm{C}$ drying to constant weight. Remove crushed, 60 mesh nylon screens set aside. This paper puts the sieving sample blending and sealed storage in a brown bottle, labeling with serial number for determination. Plant samples are accurately weighed for $4.0 \mathrm{~g}$ through dry ashing method 
and extract using HCL, and then using the graphite furnace method determination of heavy metal cadmium $(\mathrm{Cd}, \mathrm{Pb}$, $\mathrm{Cu}, \mathrm{Zn}, \mathrm{Cr}, \mathrm{Ni}$ ), the use of instruments for TAS - 986 atomic absorption spectrophotometer.

\section{RESULTS AND ANALYSIS}

\section{A. Heavy Metals Enrichment Characteristics of Poplar}

According to the experimental data from different parts of poplar can be determined in the different topsoil for different heavy metal Bioaceumu lation Factor, named BF. $\mathrm{BF}$ is a reference standard to measure the plant ability aiming at some heavy metal enrichment capacity. The calculation formula is:

$$
B F \mathrm{i}=\frac{P i}{S i}
$$

In the formula:

$\mathrm{BF}_{\mathrm{i}}$ - The enrichment coefficient of element $\mathrm{i}$

$\mathrm{P}_{\mathrm{i}}$ - Element I content in plants, $\mathrm{mg} / \mathrm{kg}$;

$\mathrm{S}_{\mathrm{i}}$ - Element in plant growth medium content $\mathrm{i}$, $\mathrm{mg} / \mathrm{kg}$

$\mathrm{BF}$ is the positive correlation relationship with plant heavy metal enrichment capability, namely the larger BF value the ability of heavy metal accumulation is stronger. Especially the aerial parts of the plant body organs, the larger enrichment capability the organs have, its ability to repair the heavy metal is stronger. A hyper-accumulation plants, plants for the $B F>1$ is one of the obvious performance characteristics.

Calculate according to Eq. 1, each part of the six kinds of heavy metals in the poplar average enrichment coefficient, shown in Table 1.

TABLE I. ENRICHMENT COEFFICIENTS OF HEAVY METALS

\begin{tabular}{|c|c|c|c|c|c|c|}
\hline Part & $\boldsymbol{C u}$ & $\mathbf{Z n}$ & $\boldsymbol{C r}$ & $\boldsymbol{N i}$ & $\boldsymbol{P b}$ & $\boldsymbol{C d}$ \\
\hline Root & 1.20 & 1.79 & 0.08 & 0.11 & 0.06 & 0.64 \\
\hline Rhizome & 0.46 & 1.31 & 0.06 & 0.03 & 0.12 & 0.26 \\
\hline $\begin{array}{c}\text { Thoracic } \\
\text { stem }\end{array}$ & 0.50 & 2.46 & 0.10 & 0.02 & 0.13 & 0.27 \\
\hline Branch & 1.23 & 3.15 & 0.05 & 0.12 & 0.09 & 0.66 \\
\hline Leaf & 1.43 & 3.18 & 0.12 & 0.17 & 0.16 & 1.19 \\
\hline
\end{tabular}

According to Table 1, the characteristic of the different heavy metal enrichment in poplar body are analyzed, as shown in Fig. 1.

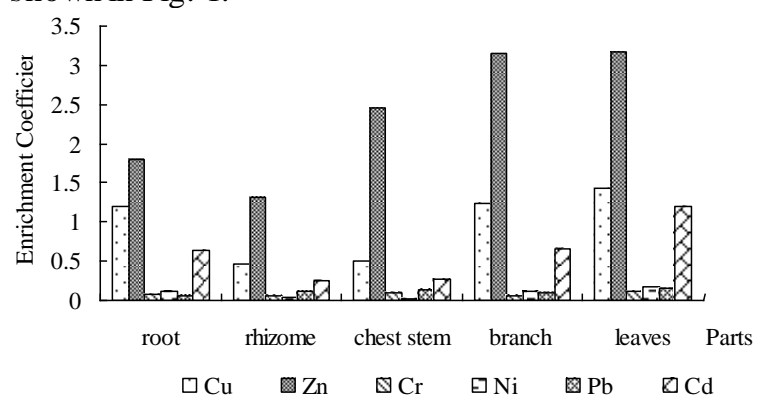

Figure 1. Enrichment characteristics of heavy metal
According to table 1 and Fig. 1: The order of $\mathrm{Cu}$ enrichment capability in poplar body is: leaf $>$ branch $>$ root $>$ thoracic stem $>$ rhizome, so we can know compared with thoracic stem and rhizome poplar leaves, branches, roots are $\mathrm{Cu}$ main enrichment parts. $\mathrm{Zn}$ in poplar body enrichment capability in the order: leaf $>$ branch $>$ root $>$ rhizome > thoracic stem, and all value of number are greater than 1, shows that whole poplar has strong enrichment for heavy metal $\mathrm{Zn}$. $\mathrm{Cr}$ in poplar body enrichment ability manifest that: leaf $>$ thoracic stem > rhizome > branch > root, and the roots of $\mathrm{Cr}$ enrichment coefficient is 1.40 , shows that the roots is the main parts of poplar for $\mathrm{Cr}$ enrichment. $\mathrm{Ni}$ in poplar body enrichment capability rank is that: leaf $>$ branch $>$ root $>$ rhizome $>$ thoracic stem, and enrichment coefficient all less than 0.5 , its stand the enrichment capability of poplar for $\mathrm{Ni}$ is weaker. The order of $\mathrm{Pb}$ enrichment capability in poplar body is: leaf $>$ thoracic stem $>$ rhizome $>$ branch $>$ root, enrichment coefficient all less than 0.5, it's also expression that the enrichment capability of poplar for $\mathrm{Pb}$ is weaker. $\mathrm{Cd}$ in poplar body enrichment capability set size in the order: leaf $>$ branch $>$ root $>$ thoracic stem $>$ rhizome, and leaf, shoot, root of enrichment coefficient is greater than 0.5 , shows that poplar leaves, twigs, roots are metal $\mathrm{Cd}$ enrichment main parts

\section{B. Heavy MetalsTransferCharacteristics of Poplar}

Transfer coefficient is a ratio of the ground and underground part of element content in the plant, the larger of transfer coefficient is, the heavy metals from the root to the different organs above ground transport ability is stronger. Transfer coefficient is greater than 0.5 , the plant can transferred most of the heavy metals to the ground, is advantageous to the heavy metal recycling. Its computation formula for:

$$
T \mathrm{i}=\frac{P u i}{P d i}
$$

In formula:

$\mathrm{Ti}$ - the transfer coefficient of element I;

Pui-Elements in the plant I part of the content on the ground, the unit $\mathrm{mg} / \mathrm{kg}$;

Pdi-The content of element I in plant underground part (full amount), the unit $\mathrm{mg} / \mathrm{kg}$.

On the basis of Eq.2, count six kinds of metal in the poplar body transfer coefficient, the results are shown in table 2 .

TABLE II. TRANSFER COEFFICIENT OF HEAVY METALS

\begin{tabular}{|c|r|r|r|r|r|c|}
\hline Part & $C u$ & $Z n$ & $C r$ & $N i$ & $P b$ & $C d$ \\
\hline Stem & 0.33 & 0.60 & 0.66 & 0.17 & 0.68 & 0.76 \\
\hline Branch & 1.26 & 1.06 & 0.42 & 0.90 & 0.70 & 0.97 \\
\hline Leaf & 1.98 & 1.23 & 0.55 & 1.38 & 1.10 & 1.77 \\
\hline $\begin{array}{c}\text { Transfer } \\
\text { coefficient }\end{array}$ & 3.57 & 2.89 & 1.63 & 2.45 & 2.54 & 3.50 \\
\hline
\end{tabular}

According to Table 2, analysis of different heavy metals in the poplar transfer characteristics, as shown in Fig. 2.

According to Table 2 and Fig. 2 shows that the capability of the transfer of heavy metals by poplar stems is: $\mathrm{Cd}>\mathrm{Pd}>\mathrm{Cr}>\mathrm{Zn}>\mathrm{Cu}>\mathrm{Ni}$; Branch's ability to transfer of 
heavy metals as follows: $\mathrm{Cu}>\mathrm{Zn}>\mathrm{Cr}>\mathrm{Ni}>\mathrm{Pd}>\mathrm{Gd}$; leaf's ability to transfer of heavy metals as follows: $\mathrm{Cu}>\mathrm{Cd}>$ $\mathrm{Ni}>\mathrm{Zn}>\mathrm{Pd}>\mathrm{Cr}$; And poplar total transfer capability of heavy metals in turn: $\mathrm{Cu}>\mathrm{Cd}>\mathrm{Zn}>\mathrm{Pd}>\mathrm{Ni}>\mathrm{Cr}$, and $\mathrm{Cu}$ transfer coefficient is the largest with $3.57, \mathrm{Cd}$ takes second place with 3.50; above all, Poplar has a strong transfercapability to $\mathrm{Cu}$ and $\mathrm{Cd}$.

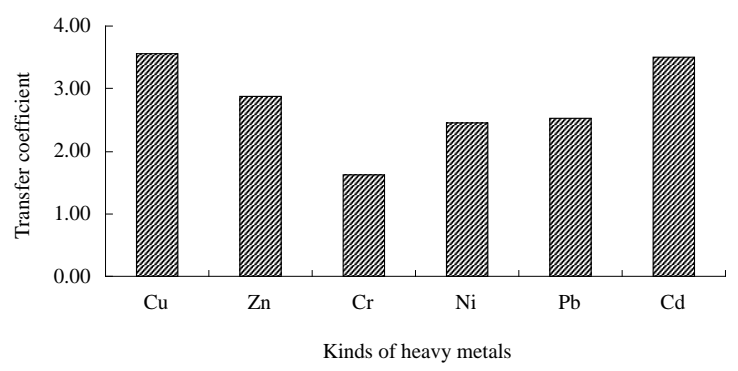

Figure 2. Transfer characteristics of heavy metal

\section{CONCLUSIONS}

Through the above analysis, draw the following conclusions:

(1) Enrichment capability of poplar to heavy metal: The order of $\mathrm{Cu}$ enrichment capability in poplar body is: leaf $>$ branch $>$ root $>$ thoracic stem $>$ rhizome, so we can know compared with thoracic stem and rhizome, the poplar leave, branch, root are $\mathrm{Cu}$ main enrichment parts. $\mathrm{Zn}$ in poplar body enrichment capability in the order: leaf $>$ branch $>$ root $>$ rhizome $>$ thoracic stem, and all value of number are greater than 1, shows that whole poplar has strong enrichment for heavy metal $\mathrm{Zn}$. $\mathrm{Cr}$ in poplar body enrichment ability manifest that: leaf > thoracic stem $>$ rhizome $>$ branch $>$ root, and the root of $\mathrm{Cr}$ enrichment coefficient is 1.40 , shows that the root is the main part of poplar for $\mathrm{Cr}$ enrichment. $\mathrm{Ni}$ in poplar body enrichment capability rank is that: leaf > branch > root > rhizome > thoracic stem, and enrichment coefficient all less than 0.5 , its stand the enrichment capability of poplar for $\mathrm{Ni}$ is weaker. The order of $\mathrm{Pb}$ enrichment capability in poplar body is: leaf > thoracic stem $>$ rhizome $>$ branch $>$ root, enrichment coefficient all less than 0.5, it's also expression that the enrichment capability of poplar for $\mathrm{Pb}$ is weaker. $\mathrm{Cd}$ in poplar body enrichment capability set size in the order: leaf > branch > root > thoracic stem > rhizo me, and leaf, shoots, root of enrichment coefficient is greater than 0.5 , shows that poplar leave, twig, root are metal $\mathrm{Cd}$ enrichment main parts.

(2) Capability of the transfer of heavy metals by poplar stems is: $\mathrm{Cd}>\mathrm{Pd}>\mathrm{Cr}>\mathrm{Zn}>\mathrm{Cu}>\mathrm{Ni}$; heavy metals transfer ability of branch as follows: $\mathrm{Cu}>\mathrm{Zn}>\mathrm{Cr}>\mathrm{Ni}>\mathrm{Pd}>\mathrm{Gd}$; heavy metals transfer ability of leaf's as follows: $\mathrm{Cu}>\mathrm{Cd}>$ $\mathrm{Ni}>\mathrm{Zn}>\mathrm{Pd}>\mathrm{Cr}$; And poplar total transfer capability of heavy metals in turn: $\mathrm{Cu}>\mathrm{Cd}>\mathrm{Zn}>\mathrm{Pd}>\mathrm{Ni}>\mathrm{Cr}$, and $\mathrm{Cu}$ transfer coefficient is the largest with $3.57, \mathrm{Cd}$ take second place with 3.50; above all, Poplar overall has a strong transfer capability to $\mathrm{Cu}$ and $\mathrm{Cd}$.

\section{ACKNOWLEDGMENT}

This research was financially supported by Innovation and entrepreneurship training programs for College Students (AH201410361108).

\section{REFERENCES}

[1] Liuyufeng. Teng jie research progress of soil heavy metal pollution. Pollution prevention and control technology, vol. A4, 2006, pp. 4245.

[2] Chaney R L, Minnie M, Li Y M, et al. Phytoremediation of soil metals. Current Opinion in Biotechnology, vol. A8, 1997, pp. 279284.

[3] Wuyanhua.The south of Beijing soil heavy metal pollution characteristics and poplar repair effect. China university of geosciences (Beijing), 2005.5

[4] Punshon T, Lepp N W, Dickinson N M. Resistance to copper toxicity in some British willows. Journal of Geochemical Exploration, vol.52, 1995,pp. 259-266

[5] [5] Pulford ID, Watson C. Phytoremediation of heavy metalcontaminated land by trees-a review. Environment International, vol29, 2003, pp. 529-540

[6] [6] Yuguoying,Wuyanyu,Wangxin ect. The heavy metals inside and out side migration cycle in Poplar body research during Poplar leaves before and after. Journal of applied ecology, vol. A2, 1996, pp. 201-208

[7] Tlustoš P, Száková J, Vysloužilová M, et al. Variation in the uptake of arsenic, cadmium, lead, and zinc by different species of willows Salix spp. grown in contaminated soils. Central European Journal of Biology, vol. A2, 2007, pp. 254-275

[8] Kuzovkina YA, Quigley MF. Willows beyond wetlands: uses of Salix L. species for environmental project s[J]. Water, Air, and Soil Pollution, vol. 162, 2005, pp. 183-204

[9] Zalesny JA, Zalesny Jr.RS, Coyle DR, et al. Growth and biomass of Populus irrigated with landfill leachate. Forest Ecology and Management. vol. A3, 2007,pp. 143-152

[10] Zalesny JA, Zalesny Jr.RS, Wiese AH, et al. Choosing tree genotypes for phytoremediation of landfill leachate using phytorecurrent selection. International Journal of Phyt oremediation, vol. A6, 2007,pp. 513-530. 